\title{
O desenvolvimento mediúnico na Umbanda: uma compreensão junguiana
}

\author{
Alexandre Frank Silva Kaitel \\ Luiz Henrique Lemos Silveira
}

\section{Resumo}

Realizamos uma pesquisa empírica para compreender as transformações subjetivas decorrentes do processo de desenvolvimento mediúnico na Umbanda. A coleta de dados ocorreu em quatro terreiros da cidade de Belo Horizonte através de vinte entrevistas semi-estruturadas e observação participante de noventa rituais. Foram entrevistados doze médiuns desenvolventes e oito sacerdotes. Os resultados foram compreendidos através da teoria junguiana e da lógica interna oferecida pelos participantes. Encontramos majoritariamente coincidências entre as postulações de Jung e de nossos sujeitos de pesquisa sobre o desenvolvimento da mediunidade. Encontramos também uma divergência, que nos levou a propor uma releitura de um aspecto da teoria do autor, embasada na compreensão umbandista do fenômeno.

Palavras-chave: Umbanda. Jung. Subjetividade. Desenvolvimento da mediunidade. Pesquisa empírica.

\section{The Development of Mediunity in Umbanda: a junguian comprehension}

\section{Abstract}

We did a research to comprehend the subjective transformations coming from the mediunity development in Umbanda. The data collection happened in four temples in the city of Belo Horizonte. We used twenty interviews and the participant observation of ninety rituals. We interviewed twelve developing mediums and eight clergymen. The results were comprehended using junguiana theory and the internal logic used by the research participants. We found mostly coincidences between Jung postulations and our research participants postulations. We also find a divergene, that guides us to propose a new understanding of one aspect of the author theory, based in the umbandist comprehension of the phenomena.

Key words: Umbanda. Jung. Subjectivity. Development of mediunity. Empirical research.

* PUC Minas. Doutor (2019) em Ciências da Religião pela PUC Minas. Atualmente é professor adjunto da Pontifícia Universidade Católica de Minas Gerais. afskaitel@gmail.com .

** Faculdade Pitágoras de Teixeira de Freitas. Pós-doutorado em Ciências da Religião Pontifica Universidade Católica de Minas Gerais (2019). luizhls@yahoo.com.br . 


\section{El desarrollo de la mediumnidad en Umbanda: una comprensión junguiana.}

\section{Resumen}

Llevamos a cabo una investigación empírica para comprender las transformaciones subjetivas resultantes del proceso de desarrollo medioista en Umbanda. La recolección de datos se realizó en cuatro terreiros en la ciudad de Belo Horizonte a través de veinte entrevistas semiestructuradas y observación participante de noventa rituales. Doce medios de desarrollo y ocho sacerdotes fueron entrevistados. Los resultados se entendieron a través de la teoría junguiana y la lógica interna ofrecida por los participantes. Encontramos principalmente coincidencias entre las postulaciones de Jung y las de nuestros sujetos de investigación sobre el desarrollo de la mediumnidad. También encontramos una divergencia, que nos llevó a proponer una relectura de un aspecto de la teoría del autor, basada en la comprensión del fenómeno por parte de Umbanda. Palabras clave: Umbanda. Jung. Subjetividad. Desarrollo de la mediumnidad. Investigación empírica.

\section{Introdução}

Este artigo é fruto de uma pesquisa empírica qualitativa onde se estudou o desenvolvimento mediúnico na Umbanda. A coleta de dados e informações foi realizada em quatro Terreiros de Umbanda da cidade de Belo Horizonte através de entrevistas semi-estruturadas e observação participante. Entrevistamos os médiuns desenvolventes, definidos para fins da pesquisa como aqueles que estão desenvolvendo sua mediunidade e não começaram a atender incorporados com todas as falanges espirituais que trabalham no Centro umbandista ao qual são vinculados, ou que fazem isso a menos de um ano, e os sacerdotes que os acompanham no processo.

Entendendo a subjetividade como aberta e em constante transformação e a mediunidade como a capacidade de um ser humano em estado não usual de consciência de acessar informações e/ou capacidades que ele não reconhece ter no estado de vigília, junto com a crença que estas informações e capacidades são oriundas do contato com algum ser extrafísico, procurou-se identificar no campo as principais mudanças subjetivas influenciadas pelo desenvolvimento da mediunidade na Umbanda e pela inserção em uma comunidade de Terreiro. Os resultados revelam mudanças subjetivas das pessoas influenciadas pelo desenvolvimento, mudanças estas que podem ser compreendidas através de uma leitura junguiana. Além de apresentarmos esta compreensão, utilizamos nossos dados empíricos para propor uma releitura da teorização junguiana sobre a incorporação de espíritos e uma indicação sobre como a incorporação de espíritos provenientes de falanges específicas promovem transformações subjetivas coerentes com as características dessas falanges. 
Iniciaremos o artigo apresentando a metodologia de coleta e análise de dados. Continuamos o artigo escrevendo sobre a Umbanda e sobre a leitura junguiana da religião. Falamos também da importância dos símbolos e rituais na prática religiosa. Depois explicitaremos alguns dos dados de campo e as coincidências e divergências destes com o que a literatura junguiana nos diz

\section{Metodologia}

Foram selecionados quatro terreiros de Umbanda para participaram da pesquisa. Um terreiro onde havia polifonia ritual, a presença de mais de uma religião no mesmo espaço físico com a participação dos mesmos sujeitos. Esse Terreiro, o Centro Espírita São Sebastião, toca Umbanda, Candomblé de Angola e Reinado. Foi neste local onde encontramos a Umbanda mais influenciada pelo Candomblé. Outros dois terreiros, a Casa de Caridade Pai Cruzeiro de Aruanda e a Casa de Pai Cipriano, conjugam as influências do Candomblé e do Espiritismo dentro do que percebemos ser a tônica usual em Belo Horizonte. No quarto terreiro, o Templo Escola Ogum 7 Espadas, encontramos a menor influência do Candomblé. Este terreiro, que se auto-intitula de Umbanda Sagrada, maior influência do Kardecismo. Esta diversidade entre as influências religiosas nos Terreiros reflete, parcialmente, a diversidade própria à Umbanda. Gostaríamos de apontar, entretanto, que devido ao grande escopo de tipos diferentes de Umbanda, o número de Terreiros pesquisados é insuficiente para abarcar todo o espectro das diferenças entre eles. Outras pesquisas que abordem o desenvolvimento mediúnico em Centros de outros tipos de Umbanda, como o Umbandaime e a Umbanda Esotérica, trariam informações complementares a essas que produzimos em nossa pesquisa.

Foram convidados a participar das entrevistas doze médiuns desenvolventes e oito líderes religiosos. Os líderes religiosos se dividem em quatro sacerdotes principais e quatro sacerdotes auxiliares, que acompanham esses médiuns em seu processo de desenvolvimento. Realizaram-se vinte entrevistas, que ao todo duraram dezesseis horas e doze minutos. As entrevistas foram gravadas e transcritas literalmente. Os entrevistados assinaram um termo de consentimento. Utilizamos entrevistas semi-estruturadas, aquelas onde há um roteiro de perguntas, mas há também flexibilidade para modificá-lo durante as entrevistas. Nosso roteiro teve apenas três perguntas norteadoras, para permitir que os sujeitos de pesquisa exponham o que percebem como essencial ao fenômeno estudado sem grandes interferências dos direcionamentos dados pelas perguntas dos pesquiadores. 
As perguntas, inicialmente, eram duas; uma abrindo e outra fechando as entrevistas: 1) Conte como começou sua história com a Umbanda; 2) Tem algo mais que gostaria de dizer sobre o desenvolvimento mediúnico? À medida que aconteceram as entrevistas e a observação participante, surgiu uma unidade de sentido que acabou sendo incorporada como nova pergunta norteadora, que tratava das modificações subjetivas ligadas à incorporação de falanges específicas. O tratamento dos dados e informações foi estruturado em quatro etapas.

Primeiro, após a transcrição das entrevistas, fazemos a leitura global do texto, buscando identificar a estrutura e a lógica interna do relato. Neste primeiro momento há uma apreensão pré-analítica do clima geral da entrevista. Na segunda etapa separaremos e categorizaremos as unidades de sentido presentes nos discursos dos entrevistados. Na terceira etapa fizemos a tradução das unidades de sentido onde se procurou correlações entre as teorias e as unidades de sentido oferecidas pelos entrevistados. $\mathrm{Na}$ quarta etapa fizemos a síntese, agrupando as unidades de sentido dentro de uma compreensão global do fenômeno estudado. As informações coletadas na observação participante também foram incluídas nesta etapa. Apresentamos uma proposta teórica onde propomos uma releitura umbandista do que Jung (2000a) postulou sobre a incorporação de espíritos.

$\mathrm{Na}$ observação participante estivemos em giras de desenvolvimento, o principal rito de desenvolvimento mediúnico da Umbanda, e outros processos e rituais realizados com esse fim. A observação participante que realizamos incluiu dois momentos distintos. O primeiro foi a observação de sessões de desenvolvimento mediúnico, ou sessões de atendimento onde ocorriam também desenvolvimentos mediúnicos. O segundo momento inclui a convivência fora dos rituais; conversas informais, nos bastidores, no café. Assistimos a aproximadamente noventa rituais durante o tempo de realização da pesquisa. Podemos dividi-los em rituais públicos, como as giras de atendimento onde ocorreram concomitantemente o desenvolvimento mediúnico, as oferendas grupais, as festas grupais e as giras de oração; e rituais esotéricos, onde apenas os médiuns, ou um subgrupo de médiuns, participaram. Rituais desse último tipo foram as giras específicas de desenvolvimento mediúnico, as oferendas individuais e algumas oferendas grupais restritas aos médiuns da casa (ligadas ao desenvolvimento ou cura de um dos médiuns ou fiéis, ou a datas litúrgicas específicas), e os cortes (sacrifícios animais).

Podemos também dividi-los entre rituais específicos para o desenvolvimento mediúnico, como as giras de desenvolvimento e os amacis (lavagem de cabeça ritual), e rituais onde o desenvolvimento mediúnico é tarefa se- 
cundária, como as giras de atendimento. Foi unânime, entre os sacerdotes, a compreensão que a participação em rituais não específicos é tão importante para os médiuns desenvolventes quanto à participação nos rituais específicos.

\section{A Umbanda}

Atualmente há uma discussão sobre a etimologia da palavra Umbanda e seus significados. Uma corrente mais exotérica a define como sendo de origem sânscrita; outra afirma que a palavra se forma a partir de ajustes de princípios adâmicos ou vatâmicos presentes na escrita ariana e na linguagem védica expressa inicialmente como Aumbhandhan, tendo o sentido de normas e ensinamentos sobrenaturais. Há ainda uma corrente mais histórica, que coloca o vocábulo como sendo proveniente do grupo linguístico de tradição Bantu (OLIVEIRA; JORGE, 2013), mais especificamente dos dialetos Umbundo, Kimbundo e Ambundo, derivando-se da palavra kimbanda, que se refere ao chefe do culto; ao feiticeiro; ao médico; ao adivinho por vezes; ou ao espaço de macumba ou mesmo o seu ritual religioso (SILVA, 1995).

A Umbanda é marcada pelo sincretismo religioso; sofrendo influências do Espiritismo kardecista, dos Candomblés, da Pajelança, do Catolicismo popular e de práticas orientais (CORRAL, 2010; LAGES, 2007; LAGES, 2003; SARACENI, 2010). A Umbanda fundamenta sua prática na crença nas inter-relações entre os mundos material/visível e espiritual/invisível, e na possibilidade dos espíritos desencarnados e encantados incorporarem-se aos médiuns e auxiliarem os seres humanos vivos através de conselhos, benzeções, banhos e tratamentos energéticos. Fundamenta também na crença das inter-relações entre seres humanos e Orixás, seres divinos associados à natureza e que acompanham e assistem os seres humanos em seu processo de desenvolvimento contínuo durante múltiplas encarnações.

A Umbanda, além de sincrética, é também não-proselitista, pois não prega conversão das pessoas que a procuram procurando auxílio; cristã, pois é baseada nos evangelhos de Cristo; espiritualista, pois realiza atendimentos espirituais através de espíritos incorporados em médiuns; e da natureza, pois considera a natureza sacra e o corpo tão importante quanto a alma.

Como acontece com todas as religiões diaspóricas de matrizes africanas, é difícil precisar quando surgiu a religião umbandista. A predominância da oralidade e a invisibilidade provocada pelo racismo religioso dificultam uma localização geográfica e temporal específica sobre o surgimento da Umbanda. Encontramos hoje três discursos diferentes sobre o surgimento da religião, que nomeamos como: relato mítico, ligado à figura de Zélio Fernandino de Morais 
como fundador da Umbanda; relato histórico, que compreende a formação da Umbanda como fenômeno social a partir da releitura urbana e moderna dos Candomblés realizadas no sudeste; relato institucional, a partir da organização de alguns princípios básicos da religião nos anos 30 e 40 do século XX.

Roger Bastide, pesquisador francês que foi professor da Universidade de São Paulo (USP) e realizou diversas pesquisas de campo sobre religiões afro-brasileiras, traça um histórico dessas religiões partindo dos Candomblés da Bahia, chegando até a Umbanda. Para o autor, as religiões diaspóricas africanas no Brasil se organizaram na Bahia como comunidades onde os descendentes dos negros e negras escravizados conviviam e se protegiam. O Terreiro refazia laços emocionais perdidos, promovia auxílio espiritual e financeiro. Assim, auxiliava na organização emocional e social das pessoas que dele participavam. Com a interiorização, e a distância física entre os fieis de religiões afro-brasileiras causada por ela, começou a ser comum que uma única pessoa, ou um grupo muito pequeno de pessoas, começasse a atender incorporado com espíritos. Neste segundo momento das religiões diaspóricas africanas perdia-se a vinculação comunitária, sobrando o auxílio imediato a problemas específicos através da consulta aos espíritos. Essas consultas eram, por vezes, uma atividade remunerada. Bastide (1971) acreditava que esta nova formação do culto, mais individualizado, tendia a aumentar as características patológicas presentes nas religiões, que não estariam mais controladas por um aspecto público comunitário. No terceiro momento, com a crescente urbanização, se formam novamente comunidades religiosas. Estas novas comunidades resgatavam algo do caráter comunitário e organizador perdido no segundo momento; apesar de já marcado pelo individualismo moderno. Esta nova leitura das religiões afro-brasileiras; moderna, urbana e com influências do espírito científico da época, promoveu no sudeste a formação da Umbanda, a partir de uma aproximação da macumba carioca - religião de matriz africana surgida nas comunidades marcadamente pobres e negras do Rio de Janeiro no século XIX onde atendimentos eram realizados por sacerdotes incorporados com espíritos - com religiões "brancas" como o kardecismo.

Ortiz (1976) aponta que a Umbanda realizou uma releitura de elementos religiosos negros, brancos e índios; a partir de uma percepção marcadamente influenciada pelos costumes da classe média urbana da época. De acordo com o autor, a Umbanda surge em um contexto social de crescente industrialização e escolarização da população. Negrão (1993) aponta raízes negras, com leitura encantada do mundo, e ética cristã, com dicotomia marcada entre bem e mal, além de princípios pragmáticos ligados à caridade, de inspiração kardecista. 
O relato institucional da fundação da Umbanda apresenta a tentativa de organização da religião e sua legitimação social, iniciada nas décadas de 30 e 40. Cumino (2015), cientista da religião e sacerdote umbandista, aponta uma relação ambígua com o Estado Novo e seu líder Getúlio Vargas. O populismo e o nacionalismo, marcas da política deste período, promoveram a industrialização e a urbanização do Brasil. É neste novo ambiente cultural que a Umbanda floresce e toma contornos parecidos com o que tem hoje. Esta valorização nacionalista não acaba com a perseguição oficial às religiões afro-brasileiras, mas a ameniza; ao mesmo tempo em que valoriza a Umbanda como religião tipicamente brasileira, segundo o espírito de época de busca por uma identidade nacional. No ano de 1934 o estado do Rio de Janeiro coloca a Umbanda sobre jurisdição do Departamento de Tóxicos e Mistificações da polícia. Esta mudança pode ser vista por um viés positivo, pois permitiu e legitimou a atuação dos Terreiros, mas também por um viés negativo, pois o registro na polícia exigia o pagamento de uma taxa (não exigida para as religiões cristãs) e permitia que a polícia fechasse Centros umbandistas cujas práticas fossem consideradas impróprias.

O relato mítico do surgimento da Umbanda discorre sobre como o médium Zélio Fernandino de Morais, na época com dezessete anos, incorpora o Caboclo das 7 Encruzilhadas dentro de uma sessão espírita kardecista e funda uma nova religião. Quando nomeamos o relato como "mítico" não estamos dizendo de algo falso ou fantasioso, segundo o significado da palavra no senso comum. Mítico, para nós, aponta para um nível diferente de significação, também verdadeira. O relato é mítico porque sua importância vem da simbologia nele utilizada, uma simbologia que indica os eixos norteadores centrais da religião, mais do que de sua veracidade histórica. Neste sentido, toda narrativa fundante de uma religião é mítica. A maioria dos Centros de Umbanda utiliza essa terceira narrativa. Dos quatro Centros de Umbanda participantes da pesquisa empírica, três utilizam apenas esse discurso, e uma utiliza tanto esse discurso quanto o discurso que nomeamos como histórico.

A Umbanda propõe o acolhimento de vivos e não vivos provenientes de substratos minoritários (em termos de poder) da sociedade. A incorporação de espíritos que foram, em alguma de suas encarnações (ou que para reforçar a simbologia da simplicidade se nomeiam como) espíritos de escravos (pretos e pretas velhas), indígenas (caboclos), crianças (erês), pessoas ligadas à vivência "da rua" e/ou a profissões pouco valorizadas (guardas, policiais, ciganos, prostitutas, malandros, boiadeiros, marinheiros) e migrantes (baianos e nordestinos) reforçam a integração de aspectos negligenciados da formação identitária do 
povo brasileiro (LAGES, 2003), tanto quanto aspectos arquetípicos pouco valorizados da personalidade dos umbandistas (LAGES, 2003; LAGES, 2007). A Umbanda nomeia de falange cada um desses grupos de espíritos que possuem vivências parecidas e são especialistas em determinado tipo de atendimento.

José Jorge de Carvalho (2005), antropólogo estudioso das religiões afrobrasileiras, afirma que a característica central da mística dessas religiões é a experiência do transe. Ele afirma que através das incorporações ocorridas durante o transe mediúnico o adepto vai introjetando formas de se relacionar com as divindades. $\mathrm{Na}$ pesquisa de campo que realizamos encontramos indícios dessas aprendizagens. Os médiuns desenvolventes adquirem novos modos de agir, similares aos das entidades pertencentes a falanges espirituais específicas (como as falanges dos pretos-velhos, dos exus e outras), a partir da incorporação dos espíritos dessas falanges.

\section{Religião na teoria junguiana}

Um dos precursores da psicologia da religião foi o psiquiatra e psicoterapeuta suíço Carl Gustav Jung (1875-1961). A proposta do autor era estudar o fenômeno religioso como expressão da mente humana, distanciando-se de abordagens metafísicas e teológicas. Jung não discute sobre a existência de Deus como ente transcendente ao ser humano, ele enfoca a experiência humana subjetiva de Deus.

A psicologia analítica é uma teoria muito utilizada na compreensão de fenômenos religiosos. Isto ocorre pela importância central do tema religião na obra de Jung, que entende que fenômenos religiosos são inerentes à psique humana, e da valorização positiva do imaginário religioso, percebido como possibilidade de promoção de saúde através da função transcendente da psique. A função transcendente "resulta da união dos conteúdos conscientes e inconscientes" (JUNG, 2000, p.1) e possibilita a compensação das unilateralidades do ego e da cultura dominante. Jung diz que é através dos símbolos que podemos acessar os arquétipos do inconsciente coletivo. A função transcendente possibilita também trazer mais vitalidade à vivência humana através da assimilação dos símbolos numinosos, carregados de energia psíquica, e uma adequação desta energia ao momento atual da vida da pessoa.

Apontamos que Jung não é um defensor das religiões, o autor suíço percebe tantos aspectos saudáveis quanto patológicas na forma que os seres humanos vivenciam a religião. Jung afirma que nos estados patológicos o contato com os símbolos dos inconscientes fragmentam o ego enquanto nos estados saudáveis esses mesmos símbolos auxiliam e promovem saúde através 
da função transcendente da psique. A assimilação da energia numinosa necessita de um continente, de uma situação ambiental e interna onde a confiança em seu próprio potencial e nos interlocutores permita um contato que não negue e nem apresse a elaboração simbólica.

Escreve Byington (1988, p.14): “a grande função do símbolo é a intermediação da consciência e do inconsciente coletivo para estruturar o ego". Os símbolos, como auto-expressões espontâneas da psique, servem também para compensar a unilateralidade com que a sociedade moderna trata os tipos de conhecimento, exacerbando a importância do saber racional em detrimento da sensibilidade intuitiva, esta última marcadamente expressa através do simbolismo. Silveira (2017, p. 68) afirma que "a religião, na perspectiva da psicologia junguiana, é uma experiência arquetípica, podendo assim, ser simbólica ou não simbólica, ligada tanto ao processo de Individuação, quanto ao impedimento do desenvolvimento da personalidade". Silveira (2017) trata como simbólica apenas as experiências que propiciam o desenvolvimento a partir da realização da função transcendente.

Jung (1984) entende que o que chamamos de mediunidade é a invasão do ego ou assimilação pelo ego dos complexos do inconsciente pessoal e dos arquétipos do inconsciente coletivo. A estrutura de personalidade postulada por Jung inclui o ego, parte operacional e centro das escolhas; o inconsciente individual, depositário de todas as vivências ocorridas com o sujeito; o inconsciente coletivo, depositário de todas as vivências ocorridas com a espécie humana. O inconsciente coletivo é composto por arquétipos, marcas deixadas pela repetição de fenômenos universais de carga emocional significativa. Arquétipos são "esquemas de pensamentos coletivos da mente humana" (JUNG, 1977, p. 75), são predisposições a reagir emocionalmente e a criar imagens similares quando expostos a situações similares. Os arquétipos possuem autonomia frente aos aspectos egóicos do sujeito. Autonomia no sentido dos arquétipos e complexos psicológicos funcionarem seguindo lógica diversa, muitas vezes percebida como exterior ao sujeito.

O autor (JUNG, 2000a) entende que os fundamentos na crença em espíritos e outras entidades são as percepções de imagens inconscientes e de sua autonomia frente ao ego. Jung (2000a) correlaciona a alma com os complexos do inconsciente pessoal. A assimilação de um complexo provocaria, segundo o autor, uma sensação de identidade e bem estar. A vivência de assimilação de complexos seria para ele um correlato ao que se chama de recuperação da alma nas religiões arcaicas. Ele correlaciona os espíritos com arquétipos do inconsciente coletivo. A assimilação de arquétipos pro- 
vocaria estranhamento, visto que o inconsciente coletivo não é da pessoa, e medo. A vivência da assimilação de arquétipos seria correlata à possessão por espíritos nas religiões arcaicas.

Esta comparação foi realizada levando em conta as experiências humanas em religiões arcaicas visitadas pelo autor na África, onde os espíritos eram temidos. Nas religiões mediúnicas modernas, alguns espíritos são temidos (os kiumbas e espíritos pouco evoluídos) e alguns são venerados (espíritos evoluídos, guias, protetores). Isto provoca reações diferentes às postuladas por Jung.

\section{Vivências simbólicas e rituais}

Um dos fenômenos mais importantes que animam as transformações ocorridas na subjetividade dos médiuns desenvolventes são os fenômenos simbólicos. O ser humano, no contato com o sagrado, estabelece através do imaginário e do uso dos símbolos uma ponte que permite o religar entre o humano e a transcendência. O imaginário e os símbolos presentes em cada religião permitem também fortalecer as ligações entre seus membros, apontando de forma imagética para fundamentos que caracterizam a cosmovisão daquela religião e seu funcionamento e criando sensações de pertencimento.

Para CROATO (2001, p.81) "o símbolo é, na ordem da expressão, a linguagem originária e fundante da experiência religiosa”. Como não conseguimos acessar diretamente o Totalmente, entramos em contato com ele via símbolos. A apresentação simbólica não esgota o transcendente, isto é impossível, mas permite aos sujeitos um contato mediado com ele, ou melhor dizendo, com uma de suas manifestações.

A principal maneira através da qual os médiuns desenvolventes entram em contato com os símbolos religiosos é a sua participação nos ritos religiosos. Os ritos umbandistas são conjuntos de ações complexas dos quais participam pessoas (vivas) e entidades.

Durante a ação ritual, é possível expressar socialmente através de suas várias linguagens todo um complexo onde o subjetivo e o objetivo, o individual e o comunitário se mesclam em manifestações de desejos, saudades, dores, alegrias, amores, ódios, medos, esperanças, desesperos. Em rituais que alternam momentos de efervescência emocional, de pausas e de movimentos, os rituais agem sobre os participantes, colocando em dinamismo corpo, espírito, imaginação, sentimentos que se traduzem em ações e práticas sociais (Vilhena, 2013, p. 517) 
Os ritos atualizam experiências míticas essenciais à vida religiosa; e transformam e ressignificam o mundo, trazendo ordem e inteligibilidade. Os rituais também respondem a desejos e problemas das pessoas e comunidades. O principal rito de Umbanda é a sessão de atendimento. Durante as sessões os fiéis conversam com os espíritos, fazem pedidos, recebem conselhos e ajudas magísticas. As ajudas magísticas acontecem quando as entidades dão passes energéticos, debelando energias negativas e/ou aumentando as energias positivas das pessoas; e quando são realizados ou ensinados rituais (nomeados de magias, macumbas, feitiços, ebós, oferendas...) para favorecer que a pessoa tenha suas demandas atendidas.

Como acessam o sagrado e seus poderes, Vilhena (2013) diz que os rituais acabam imantando os locais, pessoas e objetos que dele participam com esse poder. $\mathrm{Na}$ mesma direção do que diz a autora, o entendimento teológico umbandista afirma que a participação dos médiuns desenvolventes nos rituais os imanta com as energias das entidades participantes dos rituais, e ajuda no processo de adequação da energia do médium à energia das entidades espirituais que trabalharão incorporados com ele.

Marcel Mauss (1872-1950), um antropólogo francês muito utilizado no entendimento dos rituais religiosos, afirma que nestes as pessoas transcendem em direção à alteridade através do dar, receber e retribuir. Através dessa prática, marcada pelo simbolismo, se estabelecem contratos e alianças tanto inter-grupais quanto inter-sociais (MAUSS, 2003). Na Umbanda, as oferendas de flores, frutos, folhas, comidas e bebidas direcionadas às entidades espirituais e Orixás servem ao objetivo principal de facilitar a troca energética entre os dois planos da existência, o mundo visível e o mundo invisível (KAITEL; SANTOS, 2017). A cosmovisão bantu afirma que esses dois planos são mutuamente dependentes, e mantidos pelas trocas realizadas entre eles.

Os rituais podem servir ainda, de acordo com Vilhena (2013) como forma de angariar ou atestar poder. A participação em rituais, sua condução e/ou a determinação de como devem ser realizados, demonstram o lugar de poder ocupado por uma pessoa frente à comunidade religiosa, pois atestam a possibilidade de acesso ao sagrado que aquela pessoa tem. Na observação participante realizada foi dito, sempre à boca pequena, que alguns membros do grupo ficaram ressentidos por não terem sido chamados a participar de rituais específicos, e que ficaram com ciúme daqueles convidados. 


\section{Leitura junguiana dos dados do campo}

$\mathrm{Na}$ apresentação de nossos dados empíricos, escolhemos utilizar nomes fantasia para proteger a identidade dos entrevistados. Nomeamos os sacerdotes e sacerdotisas principais com nomes de pretos e pretas velhas, os sacerdotes e sacerdotisas auxiliares com nomes de caboclos e caboclas, e os médiuns desenvolventes com nomes de exus e pombagiras. Não há, necessariamente, relação direta entre os nomes utilizados na pesquisa e os nomes dados pelas entidades de trabalho dos médiuns e sacerdotes.

Tabela 1 - Os entrevistados e entrevistadas

\begin{tabular}{|c|c|c|c|}
\hline Nome fantasia & Idade & Escolaridade & Sexo \\
\hline Mãe Maria Conga & 70 & 2 grau & $\mathrm{F}$ \\
\hline Mãe Cambina & 54 & 2 grau & $\mathrm{F}$ \\
\hline Pai Antônio & 48 & Mestrado & M \\
\hline Pai Joaquim & 55 & Superior completo & M \\
\hline Cabocla Iara & 50 & Mestrado & $\mathrm{F}$ \\
\hline Caboclo Tupinambá & 36 & Mestrado & M \\
\hline Cabocla Jussara & 38 & Superior completo & $\mathrm{F}$ \\
\hline Caboclo Arranca Toco & 55 & Superior incompleto & $\mathrm{M}$ \\
\hline Pombagira do Maceió & 43 & Superior completo & $\mathrm{F}$ \\
\hline Pombagira Menina & 20 & Superior incompleto & $\mathrm{F}$ \\
\hline Pombagira Maria Navalha & 25 & Superior completo & $\mathrm{F}$ \\
\hline Exu Tiriri & 27 & Superior incompleto & $\mathrm{M}$ \\
\hline Pombagira da Meia Noite & 52 & 2 grau & $\mathrm{F}$ \\
\hline Pombagira7 Saias & 37 & 2 grau & $\mathrm{F}$ \\
\hline Pombagira Cigana & 39 & Superior completo & $\mathrm{F}$ \\
\hline Exu Cigano & 24 & 2 grau & M \\
\hline Pombagira Maria Padilha & 31 & 2 grau & $\mathrm{F}$ \\
\hline Exu capa preta & 44 & Mestrado & M \\
\hline Pombagira7 Encruzilhadas & 33 & Superior completo & $\mathrm{F}$ \\
\hline Pombagira do Cais & 30 & 2 grau & $\mathrm{F}$ \\
\hline
\end{tabular}

Fonte: tabela produzida pelos autores 
Apontamos no subitem sobre teoria junguiana como o contato com as imagens arquetípicas modifica os sujeitos através da função transcendente. Acredita-se que o ego, ao assimilar conteúdos inconscientes, se torna menos unilateral e se enriquece. No início do processo o contato com o inconsciente coletivo provoca desconforto, pois seus conteúdos tendem a ser percebidos como estranhos e exteriores aos sujeitos, e por serem muito numinosos (energéticos). Neste contexto um ambiente interno e externo que facilite a assimilação pode ser o diferencial entre uma experiência traumática e uma de crescimento. A experiência de desenvolvimento está ligada à possibilidade de integrar no inconsciente individual e no ego as imagens arquetípicas. Ao final do processo o sujeito que consegue assimilar as imagens arquetípicas se torna mais saudável.

$\mathrm{Na}$ Umbanda, se acredita que a aproximação das entidades modifica a energia dos médiuns. Incorporar uma entidade provoca modificações na personalidade do médium desenvolvente, pois a energia da entidade imanta o médium e provoca modificações em seu agir. Considera-se na Umbanda que os seres humanos possuem um corpo energético, além do corpo físico, e que esses dois corpos funcionam como um todo integrado. No início do processo de incorporação as modificações tendem a aparecer de forma mais polarizada, causando estranhamento; e mais restritas temporalmente, se fazendo notar mais notadamente nos dias próximos aos dias onde ocorrem as incorporações. Os médiuns mais experientes relatam modificações de personalidade mais constantes, e modificações mais sutis nos dias próximos às incorporações.

Fazendo um paralelo entre esses dois saberes, encontramos similaridades na crença da mudança da personalidade a partir da vivência com as imagens arquetípicas/entidades, e na percepção de que uma maior assimilação diminui as sensações de estranhamento com essas mudanças, que também se tornam mais sutis.

$\mathrm{Na}$ fala do caboclo Tupinambá:

Oh isso tinha mais... eu sentia mais, antes isso era mais forte, mais determinante em mim. As vezes no dia de exu eu acordava de mal humor sem muita paciência como os outros... de um tempo pra cá tem sido menos. Assim, sinto as vezes as influencias mas eu também tenho aprendido a lidar melhor que essas mudanças elas são muito do nosso ego da nossa dificuldade assim... misturar com a energia. Então eu... por exemplo, hoje é dia de exu. Exu tem uma das maiores vibrações. Se eu não afinizo muito com aquela vibração ou se eu tenho uma... uma vontade de dá coice em todo mundo... 
eu vou da coice em todo mundo, mas se eu não tenho eu só vou ficar ali né. (Caboclo Tupinambá)

\section{(E)Hoje em dia não te afeta tanto mais?}

Isso! Não me afeta tanto e à medida que a gente vai ficando também vai criando uma certa afinidade com a entidade. Você vai criando um laço com as entidades e isso vai ficando melhor e aí você vai sentindo menos esse choque com o passar dos anos. Por exemplo, antes quando eu trabalhava toda a reunião que eu incorporava eu não dormia bem a noite... nunca de quinta para sexta eu nunca dormia bem! Eu ia dormir umas três da manhã, quatro da manhã. Hoje durmo normal (Caboclo Tupinambá)

A Cabocla Iara também apontou que com o passar dos anos as modificações provocadas pela aproximação das entidades se torna mais sutil. Ela teoriza que esta sutilização se deve ao fato dos (as) médiuns mais experiente não precisarem de experiências tão intensas para perceberem o que está acontecendo.

As falanges de Umbanda congregam espíritos com habilidades e personalidades semelhantes entre si e diferentes de outras falanges. Assim, as modificações na personalidade dos médiuns tendem a ser parecidas quando da incorporação de espíritos da mesma falange. Parecidas, mas não idênticas, pois são espíritos diferentes, apesar de pertencerem à mesma falange. Além disso, a energia do médium se mantém presente e acaba modificando parcialmente a energia da entidade durante a incorporação. Na teoria junguiana considera-se, de forma similar, que apesar dos arquétipos do inconsciente coletivo serem os mesmos para todos os sujeitos, sua influência não é idêntica, pois eles são filtrados pelo inconsciente individual e pelo funcionamento egóico do sujeito.

Exemplificando, falaremos das modificações subjetivas relatadas pelos sujeitos de pesquisa quando da incorporação de uma das falanges onipresentes na Umbanda, a falange dos pretos e pretas velhas. Pretos e pretas velhas são frequentemente espíritos guias de Terreiros, e também são frequentemente entidades de cabeça dos médiuns.

Incorporar pretos velhos e pretas velhas traz, usualmente, modificações de personalidade ligados a um aumento da serenidade e da compaixão. Ocorrem também sensações corporais percebidas como similares aquelas que pessoas idosas vivenciam, mudanças em hábitos ligados ao cuidado com outros e de hábitos e preferências alimentares. Vejamos o que diz a Pombagira7 Encruzilhadas: 
É uma coisa que é um cansaço mesmo! (Pombagira7 Encruzilhadas)

(E) Um cansaço corporal?

Sim! E uma coisa de velho mesmo, que é muito assustador. As palavras mudam o jeito de falar tipo "o meu filho não mexe com isso não... fica tranquilo" (Pombagira7 Encruzilhadas)

(E) E da emoção tem algo especifico quando é velho?

Sim, fico mais sensível! Especialmente para choro se for preciso chorar, choro sem problema. (Pombagira7 Encruzilhadas)

O Exu Capa Preta, a Pombagira da Meia Noite e a Cabocla Iara também relatam mudanças corporais que antecedem os trabalhos com esta falange espiritual. A Cabocla Jussara, na mesma direção, diz se sentir cansada nas semanas quando ocorrem as incorporações de pretos e pretas velhas.

A Pombagira Maria Padilha relata ficar mais sensível às pessoas e situações. Ela acredita que esta sensibilidade favorece na aquisição de uma postura mais caridosa, e que afasta espíritos obsessores. O Exu Tiriri fala que o contato com os pretos velhos, cujas histórias de vida foram marcadas pela escravidão, o fez ser umas pessoa menos carregada, que reclama menos e não precisa tanto do reconhecimento dos outros.

Muitos morreram, né, foram humilhados, mal tratados, passaram a vida desse jeito, sem ninguém é dá um reconhecimento, pelo contrário e mesmo assim, eles encontraram o caminho da luz, da felicidade. E eu aqui buscando reconhecimento, que o outro olhe para mim e reconheça o meu valor, me sentindo inferior. E eles me mostrando assim, oh, você não sabe o que que é se sentir inferior. (Exu Tiriri)

A Pombagira do Maceió diz que nos dias antes das sessões ela vê sua preta velha andando pela escola onde leciona. Diz ainda que sente cheiro de café, mesmo sem haver café no ambiente, e que fica com muita vontade de tomar um gole da bebida, que não consome em outros momentos do mês. No tocante às emoções, ela se sente mais serena, com mais sabedoria. A Pombagira Menina também relata tomar café nas semanas de sessão de pretos e pretas velhas, apesar de normalmente não gostar da bebida. 
Tendo apresentado alguns dados sobre a incorporação da falanges dos pretos velhos, falaremos agora de algumas modificações mais globais na subjetividade.

O desenvolvimento da mediunidade na Umbanda promoveu, de acordo com quatorze dos entrevistados, algumas mudanças globais em seu devir. A Cabocla Iara entende que essas mudanças tem ligação com a vivência religiosa da caridade. Ela relata ter parado de beber, aguçado sua intuição e se tornado uma pessoa mais serena. Diz ainda ter se tornado menos materialista e mais empática.

Não se apegar tanto a coisa material, de não ter tanta picuinha, de... eh, talvez não estar tão ligado com coisas terrenas no sentido assim de... eu quero casa, eu quero carro, eu quero isso, eu quero aquilo, eu quero aquilo outro. Não estar tão voltado pra isso, estar voltado para o outro lado também. De certa forma se colocar mais no lugar do outro, de entender o sofrimento das pessoas. (Cabocla Iara)

A Pombagira 7 Encruzilhadas, na mesma direção, afirma ter se tornado uma pessoa mais calma e tranquila com o início de seu desenvolvimento mediúnico. A Pombagira do Cais conta ter se tornado mais serena também. A Cabocla Jussara relatou ter parado de beber, e diz que se tornou mais responsável com sua vida e com a vida dos outros. Jussara enfatiza que este aumento de responsabilidade tem lados positivos e negativos, os negativos ligados à perda de uma leveza e a uma auto-observação constante.

A Pombagira Menina também apontou um aspecto negativo do desenvolvimento mediúnico, uma restrição que desenvolveu a sair para se divertir com seus amigos, que reclamam que ela "vive muito para o Terreiro".

O Exu Capa Preta afirma ter perdido o medo da morte, e se tornado uma pessoa com mais fé e menos ansiedade.

E eu sempre fui uma pessoa muito ansiosa, sempre tive muita pressa de resolver as coisas, e nesse primeiro momento as vezes a mudança mais importante foi uma certa confiança nas coisas uma certa serenidade que as coisas iriam dar certo que me fez ficar um pouco menos ansioso neh no global. (Exu Capa Preta)

Pombagira Maria Padilha disse que deixou da falar mal dos outros e de fazer fofoca, além de conseguir perdoar pessoas que haviam lhe magoado e de 
ter se tornado mais caridosa. A Pombagira da Estrada relata que hoje explode menos com as pessoas que a chateiam, e que se tornou uma pessoa melhor.

A Pombagira Maria Navalha, que na adolescência sofreu com crises existenciais, encontrou um sentido após começar a desenvolver sua mediunidade. Ela também se modificou na direção de um maior senso de responsabilidade com os outros, e se tornou mais tolerante e compreensiva. O Caboclo Arranca-Toco afirma ter conseguido controlar sua raiva e começar a pensar antes de falar, e que isso ajudou muito em suas relações familiares e de trabalho.

O Exu Tiriri fala que parou de frequentar bares e de ficar com pessoas de energia pesada, e que se tornou menos influenciado pela opinião dos outros. As Pombagiras da Meia Noite e 7 Saias são outras desenvolvente que relatam ter parado de usar drogas, álcool no caso da primeira e maconha no caso da segunda.

Resumindo, podemos dizer que os médiuns relatam prioritariamente mudanças positivas provocadas pelo desenvolvimento mediúnico. Serenidade e calma são as mudanças positivas mais citadas. Um aumento da preocupação com os outros e uma maior restrição a hábitos antigos são citados por alguns como mudanças negativas, as mesmas mudanças são percebidas como positivas por outros.

Apesar dessa visão prioritariamente positiva sobre as mudanças advindas do início do trabalho com as entidades de Umbanda apareceram nas entrevistas e na observação participante falas sobre as dificuldades e medos presentes durante seu desenvolvimento. O preconceito ao qual se expõe os médiuns foi apontado como aspecto social negativo do desenvolvimento da mediunidade. As dúvidas sobre o quanto o médium iniciante consegue permitir que a entidade espiritual se expresse sem interferir, e a responsabilidade por direcionar a vida daqueles que buscam os atendimentos foram aspectos negativos internos apontados na pesquisa empírica.

É possível levantarmos a hipótese de que esta visão global positiva prevalece entre aqueles que escolheram continuar o processo, e que médiuns que começaram a se desenvolver e interromperam seu desenvolvimento tenham visões globais negativas sobre o mesmo. Para dirimir esta dúvida se fazem necessárias outras pesquisas, já que médiuns que desistiram de se desenvolver não fizeram parte de nossa amostra. 


\section{Considerações finais}

Inicialmente gostaríamos de dizer que a leitura junguiana de fenômenos religiosos não coincide completamente com a leitura religiosa desses fenômenos. A leitura junguiana trata os fenômenos como manifestações subjetivas, enquanto as leituras religiosas o tratam como manifestações de um sagrado existente objetivamente. Esta diferença pode chatear alguns religiosos, que sentiriam que sua verdade estaria sendo negligenciada pelo pesquisador. Apesar dessa possibilidade, a maioria dos religiosos percebe a leitura junguiana como respeitosa.

$\mathrm{Na}$ apresentação de nossos dados de campo escolhemos não diferenciar os discursos com informações científicas, observáveis, como as mudanças comportamentais e de hábitos alimentares, dos discursos com informações teológicas, como os que dizem da sincronização energética do médium com as entidades espirituais. Fazemos esta diferenciação apenas aqui nas considerações finais como forma de expressar ao mesmo tempo a valoração igualitária das duas narrativas e as diferenciações existentes entre elas.

Nossos dados empíricos apontam muitas coincidências com as colocações junguianas. A principal delas é a possibilidade de modificações na subjetividade do médium desenvolvente a partir de seu contato com as entidades umbandistas/símbolos arquetípicos ocorridas durante as incorporações. O enriquecimento de suas vivências através da função transcendente é outra coincidência, assim como a percepção de que essas transformações ocorrem de maneira mais intensa e turbulenta no início do processo e vão se tornando mais sutis e equilibradas a partir da assimilação progressiva da energia numinosa.

Encontramos também uma pequena divergência com o autor. Jung correlaciona os espíritos com arquétipos do inconsciente coletivo. Devido ao fato do inconsciente coletivo ser exterior ao sujeito, pertencente à humanidade e não a um sujeito particular, a assimilação de arquétipos provocaria estranhamento e algum mal estar. Jung correlaciona a vivência da assimilação de arquétipos à possessão por espíritos, vivência carregada de medo. Esta comparação foi realizada levando em conta as experiências humanas em religiões arcaicas africanas com as quais ele entrou em contato em imersões etnográficas que realizou no continente. Nestas religiões os espíritos são temidos. Entendemos que esta característica cultural direcionou a compreensão junguiana e o fez considerar universal uma vivência socialmente definida, um mal estar ligado à incorporação de espíritos, percebido por ele na África. 
Nas religiões mediúnicas modernas, como o Espiritismo Kardecista e a Umbanda, alguns espíritos são temidos (os kiumbas e espíritos pouco evoluídos) e alguns são venerados (espíritos evoluídos, guias, protetores). Isto provoca reações diferentes às postuladas por Jung quando se assimilam arquétipos ligados a espíritos valorados positivamente. Propomos uma adaptação da leitura junguiana, onde os espíritos venerados seriam percebidos como exteriores aos sujeitos e autônomos, por serem imagens arquetípicas, mas sua assimilação seria facilitada por aspectos culturais e por aspectos do inconsciente individual dos participantes, promovendo sentimentos de completude e bem estar. Em nossa pesquisa empírica predominaram sensações positivas quando da incorporação de entidades umbandistas pelos médiuns desenvolventes. Podemos supor que as memórias de incorporações e rituais vistos durante a vida do sujeito influenciaram na construção de complexos ligados às imagens culturalmente ligadas às entidades, que filtrariam e dariam mais familiaridade às imagens arquetípicas além de trazer um continente que indicaria uma maneira própria daquela entidade se portar durante a incorporação. Isto aconteceria devido à capacidade de assimilação dos conteúdos inconscientes ser facilitada pelos rituais e sua organização e pelo entendimento da incorporação como tendo conotação positiva, como trabalho caritativo.

Gostaríamos de apontar também que mesmo nas religiões modernas a incorporação de Kiumbas gera mal estar e estranhamento. A valorização negativa dessas entidades espirituais nos parece ser ponto central para compreendermos esta diferença de sensações provocada pela sua incorporação em comparação às sensações provocadas pela incorporação de espíritos guias e guardiões.

Finalizando, gostaríamos de explicitar a compreensão que os resultados de uma pesquisa empírica precisa sempre ser levada em conta no contraste com outras pesquisas realizadas sobre o mesmo objeto de conhecimento. Assim, entendemos que nossos achados não configuram uma verdade última, são apenas uma contribuição para a discussão sobre o processo de desenvolvimento mediúnico.

\section{Referências}

BASTIDE, Roger. As religiões africanas no Brasil. São Paulo: Pioneira, 1971.

BYINGTON, Carlos. Dimensões Simbólicas da Personalidade. São Paulo: Ed. Atica, 1988.

CARVAlHO, J. J.. A Mística Afro-brasileira. Ihu On Line, São Leopoldo, n.133, p. 23-25, 2005. 
CORRAL, Janaina A. As Sete Linhas da Umbanda. São Paulo: Universo dos livros, 2010.

CROATTO, José S. As linguagens da experiência religiosa: uma introdução à fenomenologia da religião. São Paulo: Paulinas, 2001.

CUMINO, Alexandre. História da Umbanda: uma religião brasileira. São Paulo: Madras, 2015.

JUNG, Carl G. A Função Transcendente. In JUNG, Carl G. A Natureza da Psique. Petrópolis: Vozes, p.1-23, 2000.

JUNG, Carl G.. O arquétipo no simbolismo do sonho. In JUNG, Carl G e col.. O Homem e Seus Símbolos. Rio de Janeiro: Novas Fronteiras, p. 67-92, 1977.

JUNG, Carl G. Os Fundamentos Psicológicos da crença nos espíritos. In JUNG, Carl G. A Natureza da Psique. Petrópolis: Vozes, p.239-254, 2000a.

JUNG, Carl G.. Psicologia e Religião. Petrópolis: Vozes, 1984.

KAITEL, Alexandre F. S.; SANTOS, Guaraci M. Conhecendo a umbanda: uma tipologia sob o prisma Bantu. Diversidade Religiosa, v. 7, p. 60-87, 2017.

LAGES, SONIA R. C. .Entre Iracema e a Pomba-gira Maria Padilha - a trajetória criativa da psyque. Revista Mandrágora, São Bernardo do Campo - SP, v. 1, p. 1-7, 2007.

LAGES, SONIA R. C.. Exu - Luz e sombras - um estudo psico-junguiano da linha de Exu na Umbanda. Juiz de Fora: Clio Edições Eletrônicas, 2003.

MAUSS, Marcel. Sociologia e Antropologia. São Paulo: Cosac \&Naify, 2003.

NEGRÃO, Lísias Nogueira. Umbanda: entre a cruz e a encruzilhada. In: Tempo Social Revista de Sociologia da USP, vol. 5, 1993, p. 113-122.

OLIVEIRA, Irene Dias de; JORGE, E. F. C. Espiritualidade umbandista: recriando espaços de inclusão. Revista Horizonte, Belo Horizonte, v. 11, n. 29, p. 29-52, jan./mar. 2013.

ORTIZ, Renato. A morte branca do feiticeiro negro. In: Cadernos CERU, vol. 9, 1976, p. 119- 125.

SARACENI, Rubens. Código de Umbanda. São Paulo: Madras, 2010.

SILVA, Vagner G. Orixás da metrópole. Petrópolis: Vozes, 1995.

SILVEIRA, Luiz Henrique Lemos. Perspectivas junguiana sobre a religião na contemporaneidade. 2017. 197f. Tese (Doutorado) - Programa de Pós-Graduação em Psicologia da Pontifícia Universidade Católica de Minas Gerais.Belo Horizonte, 2017.

VILHENA, Maria Angela. Ritos Religiosos. In PASSOS, João; USARSKI, Frank. Compêndio de Ciência da Religião. São Paulo: Paulinas: Paulus, 2013, p. 513-524.

Submetido em: 8-7-2020

Aceito em: 21-5-2021 